\title{
The Albanian Geomagnetic Repeat Station Network at 1994.75
}

\author{
Massimo ChiapPini ${ }^{1}$, Osvaldo Battelli ${ }^{1}$, Salvatore Bushati ${ }^{2}$, Guido Dominici ${ }^{1}$, \\ Bejo DUKA ${ }^{3}$, and Antonio MELONI ${ }^{1}$ \\ ${ }^{1}$ Istituto Nazionale di Geofisica, Roma, Italy \\ ${ }^{2}$ Albanian Geological Society, Tirana, Albania \\ ${ }^{3}$ Physics Department of University, Tirana, Albania
}

(Received April 9, 1996; Revised January 7, 1997; Accepted January 29, 1997)

\begin{abstract}
A new national geomagnetic network of repeat stations for total field $F$, horizontal component $H$, vertical component $Z$ and declination $D$ has been established in a collaboration between the Albanian Geological Society (Center for Geochemistry and Geophysics), the Tirana University (Albania) and the Istituto Nazionale di Geofisica (Italy). From the observed magnetic field elements all repeat stations were referred to Epoch 1994.75 and normal reference fields were computed in the form of 1st order polynomials in latitude and longitude. An overview of all work, including a brief history of the Albanian magnetic measurements, magnetic survey results, normal fields and secular variation estimates is presented.
\end{abstract}

\section{Introduction}

Geomagnetic field measurements are an important and cost effective supplement to the magnetic observatory data. Although some regions of the world, like for example Western Europe, are generally well covered by both observatories and repeat stations, others are poorly or very poorly investigated. Detailed reports for modern national magnetic repeat station surveys for Western Europe can be found, for example in Schulz and Beblo (1991), Barraclough (1992), Gilbert (1994), Reader and Kerridge (1995). Other areas like the Balkanian peninsula, and especially Albania, lack of good coverage.

The first geomagnetic observations in Albania were performed during the 2nd World War, in 1942, for the European Magnetic Declination Atlas, Epoch 1944.5 (Bock, 1948). These observations included declination $D$, horizontal intensity $H$ and magnetic inclination $I$ measured at 65 sites which were not uniformly distributed. Later, in 1961, the Potsdam Geomagnetic Institute (former DDR) expedition performed a survey covering part of the Albanian territory. The campaign provided measurements on 13 points. The 1942 data survey were reduced to the Epoch 1961.0 by Bolz (1963), who computed the secular variation for this area using Rössiger's data (Rössiger, 1941). Thus, a normal reference field in the form of an analytical expression was also calculated for $D, H$ and the vertical component $Z$. Nevertheless, combination of these two epochs did not cover the entire Albanian territory; the southern part of the country was not investigated yet.

In 1990, the Geophysics Enterprise of Tirana carried out measurements of the total intensity $F$ and the vertical component $Z$ of the Earth's magnetic field at 34 stations. Duka and Bushati (1991) computed the normal reference field for $Z$ and the total intensity $F$ for the Epoch 1990.4.

The first complete three-component magnetic survey covering all Albania has been carried out between September and October 1994 within the frame of a joint project involving the Istituto Nazionale di Geofisica (Italy), the Institute of Geochemistry and Geophysics of Tirana and the Physics Department of Tirana University. In this paper, magnetic survey operations, data analysis and discussion of this late survey main results are presented. 


\section{Magnetic Survey and Measurements Reduction}

The survey has been performed measuring the magnetic field elements at 10 stations. The repeat stations have been chosen according to the basic requirements in magnetic surveys, and recently described by Newitt et al. (1996):

1. lack of surrounding artificial disturbances;

2. exclusion of areas characterized by large surface anomalies;

3. sufficient number of reference points for the exact determination of the geographic north at each site.

A list of the basic information for each station, marked on the ground with a pillar, is shown in Table 1. The sketch maps with the locations of the observing points for 1990 (only $F$ measurements) and 1994 surveys are shown in Figs. 1 and 2, respectively. Detailed information on the positions on a topographic map, reference marks and azimuths and whatever is necessary for locating these sites from the 1994 survey, is available in a technical report (Battelli et al., 1997).

Equipment used during the survey included (i) a proton precession magnetometer for determination of the magnetic field total intensity $F$; (ii) a DI fluxgate theodolite for magnetic inclination and declination measurements and (iii) a gyroscope theodolite for the determination of geographic north.

Each station has been surveyed performing at least ten complete measurements of $D, I$ and $F$. This procedure took approximately 2 hours, and was preferably performed in the early morning or late afternoon, in order to avoid daily variation effects. Then the horizontal $H$ and vertical $Z$ components were computed from $F, D$ and $I$ values.

The gyro-theodolite was used to precisely locate the declination azimuth marks at each measurement point, so that when observations will be repeated at a later time, there will be no error caused by spatial variations of the field. Each repeat station point was marked with a specially constructed pillar and absolute measurements were carried out above the center of this station marker.

The observations were performed between September and October of 1994 and then reduced to Epoch 1994.75 using data from the Italian geomagnetic observatory L'Aquila $\left(42.38^{\circ} \mathrm{N}\right.$, $13.32^{\circ} \mathrm{E}$ ) which is about $500 \mathrm{~km} \mathrm{NW}$ of Tirana. To monitor geomagnetic activity during the survey within the region under investigation Tirana geomagnetic time variations were recorded by means of a portable fluxgate three component magnetometer installed in a quite shelter close to Tirana. A first view comparison of these data with L'Aquila observatory has not shown signif-

Table 1. Names, coordinates and measured magnetic field values of repeat stations of the 1994 Albanian Magnetic Survey.

\begin{tabular}{lcccccc}
\hline Station & Latitude & Longitude & Altit.(m) & $I$ & $D$ & $F(\mathrm{nT})$ \\
\hline Tiranë & $41^{\circ} 18^{\prime} 55^{\prime \prime}$ & $19^{\circ} 49^{\prime} 46^{\prime \prime}$ & 127 & $57^{\circ} 49.8^{\prime}$ & $2^{\circ} 06.4^{\prime}$ & 46101.6 \\
Elbasan & $41^{\circ} 06^{\prime} 08^{\prime \prime}$ & $20^{\circ} 00^{\prime} 44^{\prime \prime}$ & 340 & $57^{\circ} 38.1^{\prime}$ & $2^{\circ} 09.0^{\prime}$ & 46035.1 \\
Shkodër & $42^{\circ} 03^{\prime} 03^{\prime \prime}$ & $19^{\circ} 29^{\prime} 17 \prime$ & 85 & $58^{\circ} 39.3^{\prime}$ & $2^{\circ} 05.4^{\prime}$ & 46315.8 \\
Sarandë & $39^{\circ} 52^{\prime} 30^{\prime \prime}$ & $20^{\circ} 01^{\prime} 17^{\prime \prime}$ & 193 & $56^{\circ} 12.9^{\prime}$ & $2^{\circ} 06.1^{\prime}$ & 45653.3 \\
Vlorë & $40^{\circ} 24^{\prime} 00^{\prime \prime}$ & $19^{\circ} 28^{\prime} 47^{\prime \prime}$ & 10 & $56^{\circ} 46.5^{\prime}$ & $2^{\circ} 06.0^{\prime}$ & 45798.9 \\
Pogradec & $41^{\circ} 03^{\prime} 48^{\prime \prime}$ & $20^{\circ} 36^{\prime} 47^{\prime \prime}$ & 935 & $57^{\circ} 38.4^{\prime}$ & $1^{\circ} 59.7^{\prime}$ & 45955.0 \\
Kukës & $42^{\circ} 04^{\prime} 28^{\prime \prime}$ & $20^{\circ} 24^{\prime} 46^{\prime \prime}$ & 330 & $58^{\circ} 37.8^{\prime}$ & $1^{\circ} 48.6^{\prime}$ & 46363.6 \\
Peshkopi & $41^{\circ} 40^{\prime} 35^{\prime \prime}$ & $20^{\circ} 26^{\prime} 02^{\prime \prime}$ & 680 & $58^{\circ} 14.2^{\prime}$ & $2^{\circ} 17.5^{\prime}$ & 46230.1 \\
Rubik & $41^{\circ} 45^{\prime} 55^{\prime \prime}$ & $19^{\circ} 46^{\prime} 56^{\prime \prime}$ & 90 & $58^{\circ} 19.4^{\prime}$ & $2^{\circ} 56.5^{\prime}$ & 46498.1 \\
Korçe & $40^{\circ} 37^{\prime} 11^{\prime \prime}$ & $20^{\circ} 47^{\prime} 34^{\prime \prime}$ & 980 & $57^{\circ} 08.8^{\prime}$ & $2^{\circ} 14.6^{\prime}$ & 45914.0 \\
\hline
\end{tabular}




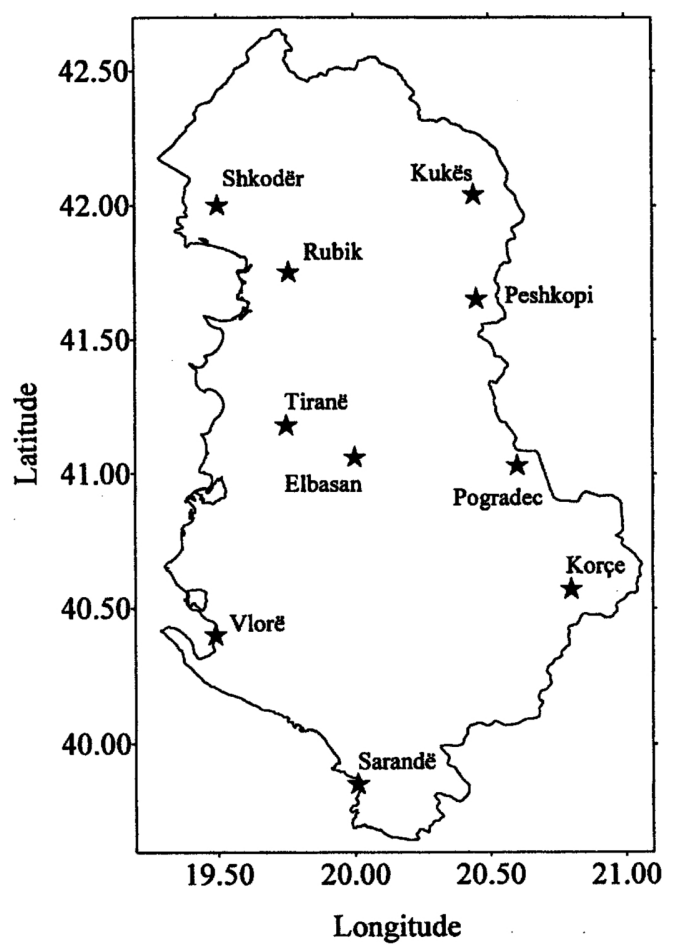

Fig. 1. Location of 10 stations deployed during the 1994 survey.

icant differences for what regards time variations reduction. In view of future enrichment of the Albanian network of repeat stations and reoccupation, L'Aquila observatory data were used for data reduction. For measurements reduction of magnetic elements, the following expression was used:

$$
E_{s}^{94.75}=E_{\mathrm{obs}}^{94.75}+\left(E_{s}^{t}-E_{\mathrm{obs}}^{t}\right)
$$

Here $E_{s}^{t}$ is the value of a generic element $E$ of the field, observed or determined at the station $s$ at time $t ; E_{\mathrm{obs}}^{t}$ is the value of $E$ recorded at the observatory at the same time $t ; E_{\mathrm{obs}}^{94.75}$ is the observatory value of $E$ for the Epoch 1994.75; this value is obtained on the basis of hourly means of the studied range of time. $E_{s}^{94.75}$ is the value of $E$ at the station $s$ reduced to 1994.75 (see for example Meloni et al., 1994). Each measurement was reduced to 1994.75 and then all reduced values were averaged to obtain one value of each field element for each repeat station. This reduction has been performed by linear interpolation between DGRF-90 and IGRF-95 models. Table 1 lists all the measured element values reduced to 1994.75 and the coordinates for the deployed repeat stations.

Another step of the data processing procedure is a reduction of all data (with the exception of angular elements) to the sea level, since the normal reference field (see below) is conventionally referred to sea level. Therefore any element $E_{s}$ at elevation $h$ is corrected considering only the dipolar contributions by:

$$
\Delta E=\frac{3 E h}{R}
$$

$R$ is the ideal spherical Earth radius $R=6371.2 \mathrm{~km}$. 


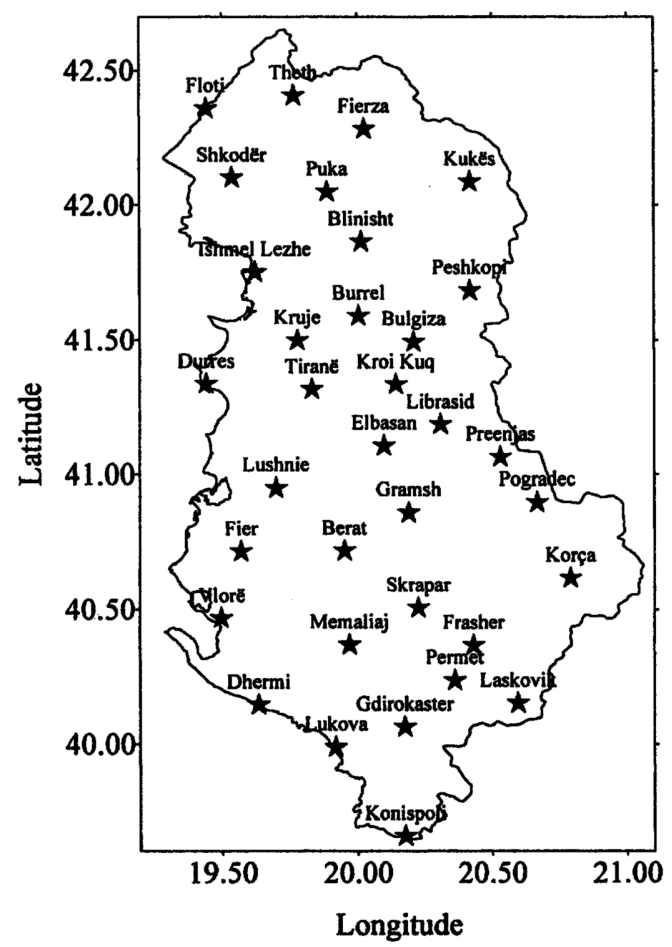

Fig. 2. Location of 34 stations deployed during the 1990 survey.

\section{Normal Reference Field and Secular Variation}

The geomagnetic field elements, measured over a network of survey stations are used for the computation of the normal reference fields after reduction and removal of external contributions. These are expressed by means of an analytical relation representing the best fit to all measured data of the Earth's magnetic field elements, acquired in the investigated region. The normal field is intended to represent the main field and then is expected to be mainly due to the magnetic sources located in the Earth's core. Based on the Bullard's rule of equivalent degree (Bullard, 1967), the model of the normal field in Albania is a first-degree polynomial in longitude and latitude; the expression for a given magnetic element $E$ is:

$$
E=a_{0}+a_{1} \phi+a_{2} \lambda
$$

where $\phi$ and $\lambda$ are geographic latitude and longitude respectively. All coordinates are relative to a reference location $\left(41^{\circ} \mathrm{N}, 20^{\circ} \mathrm{E}\right)$, almost in the centre of the area covered by the survey. The coefficients $a_{0}, a_{1}$ and $a_{2}$ are unknown variables to be determined from the observational values.

Table 2 shows the normal field coefficients over Albania for two different epochs, 1990.4 and 1994.75, corresponding to the last two surveys described above. For the total intensity $F$, the 1994.75 model has been slightly improved, in terms of quantity of data, by considering the measurements carried out in 1990 (Duka and Bushati, 1991) extrapolated to 1994.75 (Fig. 3). Therefore the number of stations was increased up to 44 with a better coverage of the national territory. As shown in Table 2, the two sets of coefficients, $F_{10}$ and $F_{44}$, relative to the same epoch but computed with 10 and 44 stations respectively, are not significantly different.

By definition, the secular variation is the first time derivative of the main geomagnetic field. 
Table 2. Coefficients of the normal reference field in Albania for the Epochs 1990.4 and 1994.75; the subscript of $F$ indicates the number of stations used for the model. Latitude and longitude are referred to $41^{\circ} \mathrm{N}, 20^{\circ} \mathrm{E}$.

\begin{tabular}{crrrr}
\hline Element & \multicolumn{1}{c}{$a_{0}$} & \multicolumn{1}{c}{$a_{1}$} & \multicolumn{1}{c}{$a_{2}$} & Epoch \\
\hline$F_{10}$ & 46028.8 & 5.757 & -0.215 & 1994.75 \\
$F_{44}$ & 46028.8 & 5.710 & 0.718 & 1994.75 \\
$F_{34}$ & 45891.8 & 5.113 & 1.150 & 1990.40 \\
$I$ & 3449.35 & 1.103 & 0.061 & 1994.75 \\
$D$ & 131.09 & 0.045 & -0.121 & 1994.75 \\
\hline
\end{tabular}

Table 3. Coefficients of the secular variation normal field in Albania for the interval 1990.4 and 1994.75; latitude and longitude are referred to $41^{\circ} \mathrm{N}$ and $20^{\circ} \mathrm{E}$ respectively.

\begin{tabular}{ccccc}
\hline Element & $a_{0}$ & $a_{1}$ & $a_{2}$ & Epoch interval \\
\hline$F(\mathrm{nT})$ & 167.82 & 0.137 & -0.099 & $1990.0-1994.75$ \\
\hline
\end{tabular}

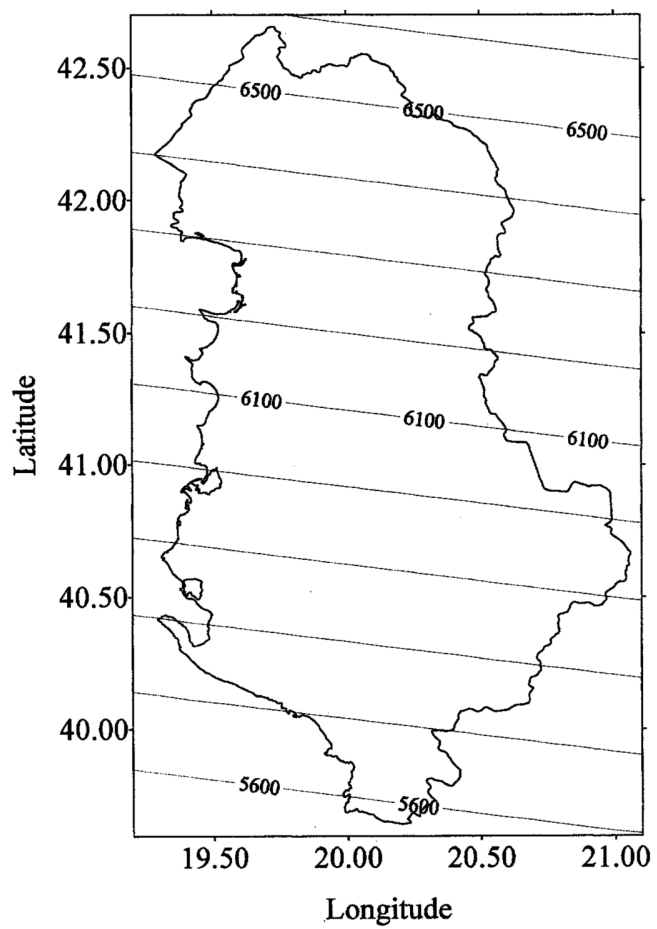

Fig. 3. Contours of the Albanian normal field for total intensity $F$, (nT), calculated from 44 stations; (value $+41,000 \mathrm{nT}$ ).

Absolute measurements, repeated at a given station, allow an estimation of secular variation at that site by finite differences. The repeat station surveys allow us to determine spatial variability of the secular variation. An attempt of secular variation estimation for the total intensity $F$ has been made, by using data from the surveys over Albania of 1990 and 1994 respectively. Table 3 
lists the coefficients of the secular variation normal field for the interval 1990.4 and 1994.75.

\section{Conclusions}

It is widely accepted that national magnetic surveys are important for the description of the main magnetic field evolution and for crustal residual estimation. Permanent magnetic observatories provide the most accurate data but because they are not well distributed on the Earth's surface, repeat stations are required to supplement observatory data. In the present paper, the first repeat station network in the Albanian territory has been described. A magnetic field model for this area, equivalent to a spherical harmonic expansion with degree $N=170$, was presented and described; for this model consequently the minimum spatial wavelength that can be represented is about $250 \mathrm{~km}$. This could be explained by the fact that the area under investigation is relatively small and a first degree polynomial representation is even redundant. Although the model could contain a small contribution due to the sources located in the lower crust, it provides a good estimation of the main field. A thorough comparison has been performed. In Fig. 4 the comparison with the IGRF, 1995 revision (IAGA Working Group V-8, 1996) is shown. The zero line of difference between IGRF and proposed magnetic model crosses the Albanian territory at the west side of the Country; the maximum difference between the two models is about $+70 \mathrm{nT}$, with positive gradient directed eastward. This relatively large difference can be due to the fact that the data shown in the present paper have not been taken into account for the development of the IGRF-95 model. On the other hand, the serious lack of magnetic data in some Countries of

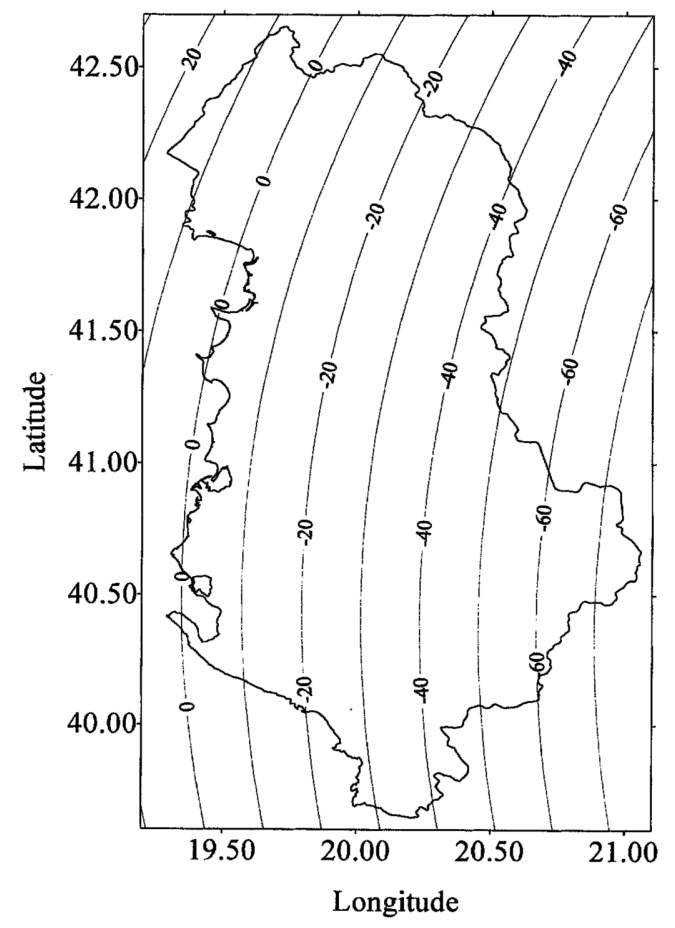

Fig. 4. Differences between Albanian normal field and IGRF, 1995 revision reference field, for total intensity $F$ expressed in $\mathrm{nT}$. 
Central and Eastern Europe affects the validation of IGRF in this part of the continent. Together with permanent observatory data, the new Albanian magnetic survey data will contribute to the improvement of global models. The data used in the present paper have already been sent to the World Data Center, and will be soon available on the World Wide Web at the Istituto Nazionale di Geofisica Web site, Roma Italy (URL http://www.ingrm.it). They will be used by the IAGA Working Group V-8 to improve the DGRF-95, for the area of the Balkanian peninsula.

The authors thank A. De Santis for his useful suggestions.

\section{REFERENCES}

Barraclough, D. R., Reoccupation of the UK regional geomagnetic repeat station network in 1963 and 1964 , British Geological Survey Technical Report, Geomagnetism Series, WM/92/22, 10 pp., 1992.

Battelli, O., M. Chiappini, S. Bushati, and B. Duka, La rete magnetica albanese (Rrjeti Magnetik Shqiperise), Publ. Istituto Nazionale di Geofisica, (in Italian and Albanian), 1997 (in press).

Bock, R., Atlas of magnetic declination of Europe for Epoch 1944.5. Washington: Army Map Service, 1948.

Bolz, H., Ergebnisse geomagnetischer Felmessungen in Albanien, Gerlands Beiträge zur Geophysik, 72, 266-271, 1963.

Bullard, E. C., The removal of trend from magnetic surveys, Earth Planet. Sci. Lett., 2, 293-300, 1967.

Duka, B. and S. Bushati, The normal geomagnetic reference field and the I.G.R.F. over Albania, Bollettino di Geofisica Teorica ed Applicata, 33, 129-134, 1991.

Gilbert, D., Campagne de mesure de répétition de la France (1986-1987), in Observations Magnétique, Bulletin No. 5, BCMT, France, 5-34, 1994.

IAGA Division V, Working Group 8, International Geomagnetic Reference Field, 1995 Revision, Geophys. J. Int., 125, 318-321, 1996.

Langel, R. A., The main field, in Geomagnetism, edited by J. A. Jacobs, 1, 249-512, 1987.

Meloni, A., O. Battelli, A. De Santis, and G. Dominici, The 1990.0 magnetic repeat station survey and normal reference fields for Italy, Annali di Geofisica, 37 (5), 949-967, 1994.

Newitt, L. R., C. E. Barton, and J. Bitterly, Guide for magnetic repeat station surveys, IAGA Working Group, 1996 (in press).

Reader, E. M. and D. J. Kerridge, UK regional magnetic repeat station network description, British Geological Survey Publication, 1995.

Rössiger, M., Das erdmagnetische Normalfeld der Vertikalintensität für Mitteleuropa, Epoche 1941.5, Beitr. angew. Geophys., 9, 1941.

Schulz, G. and M. Beblo, Results of the geomagnetic survey of the Federal Republic of Germany in 1982, HHI Report, 22, 87-98, 1991. 